\title{
Điều tra và ghi nhận nhóm côn trùng gây hại nấm bào ngư (Pleurotus pulmonarius) trồng ở Thành phố Hồ Chí Minh và Đồng Nai \\ Survey and identification of insect pests damaging the cultivation of oyster mushroom (Pleurotus pulmonarius) in Ho Chi Minh City and Dong Nai province
}

\author{
Nguyễn Thị Thùy Dương ${ }^{1 *}$, Lê Thị Thùy $\mathrm{Nhi}^{1}$, Ngô Thùy Trâm ${ }^{1}$, Dương Hoa Xô ${ }^{1}$ \\ ${ }^{1}$ Trung tâm Công nghệ Sinh học Thành phố Hồ Chí Minh, Việt Nam \\ *Tác giả liên hệ, Email: nguyenduongbiology@gmail.com
}

\section{THÔNG TIN}

DOI: $10.46223 / \mathrm{HCMCOU}$

JS. tech.vi.13.1.449.2018

Ngày nhận: 28/07/2018

Ngày nhận lại: 08/08/2018

Duyệt đăng: 15/10/2018

Tù khóa:

coleoptera, collembola, côn trùng hại nấm, diptera

Keywords:

coleoptera, collembola, diptera, insect pests of mushroom

\section{TÓM TÁT}

Dịch hại côn trùng trên nấm trồng đang xuất hiện phổ biến và gây hại nghiêm trọng cho ngành trồng nấm. Nghiên cứu này đã tiến hành điều tra các trại trồng nấm bào ngư tại Thành phố Hồ Chí Minh (TP.HCM) và Đồng Nai về tình hình côn trùng gây hại, khoảng thời gian côn trùng xuất hiện nhiều. Kết quả điều tra ghi nhận côn trùng gây hại xuất hiện nhiều thuộc bộ Coleoptera, Diptera, Collembola. Vào mùa côn trùng xuất hiện nhiều (tháng 02 - tháng 05 ), các trại trồng bào ngư tại TP.HCM có năng suất giảm từ $20 \%$ đến $50 \%$. Tỷ lệ năng suất giảm từ $30 \%$ đến $90 \%$ vào mùa côn trùng xuất hiện nhiều (tháng 03 tháng 06) ở các trại trồng bào ngư tại Đồng Nai.

ABSTRACT
Insect pests of mushrooms are becoming more common;
therefore, they cause severe damage to mushroom cultivation.
This study surveyed Mushroom Farms in Ho Chi Minh City
and Dong Nai province not only for mushroom-damaging
insects but also for their frequent occurrence. The result
recorded insect pests of Pleurotus pulmonarius mainly
belonging to three orders (Coleoptera, Diptera, and
Collembola). In the season of many existing insects, the
productivity rate of Mushroom Farms in Ho Chi Minh City
from February to May decreased from $20 \%$ to 50\% and in
Dong Nai province from March to June declined from $30 \%$ to
90\%.




\section{Mở đầu}

Nước ta có tiềm năng lớn về sản xuất nấm ăn và nấm dược liệu do có nguồn nguyên liệu trồng nấm phong phú, nguồn lao động nông thôn dồi dào, điều kiện thời tiết thuận lợi cho phát triển nhiều chủng loại nấm và có thể trồng nấm quanh năm, thị trường tiêu thụ ngày càng mở rộng. Trên cơ sở đó, nấm ăn, nấm dược liệu được đưa vào "Danh mục sản phẩm quốc gia thực hiện từ năm 2012 thuộc Chương trình phát triển sản phẩm quốc gia đến năm 2020" theo quyết định số 439/QĐ-TTg ngày 16/4/2012. Tuy nhiên, ngành trồng nấm cũng đang đối mặt với những dịch hại nguy hiểm làm thất thu năng suất đáng kể. Tại hội thảo "Trao đồi kỹ thuật, cơ hội và thách thức của ngành nấm Việt" được tổ chức tại Đà Lạt (2016) cũng có nhiều báo cáo ghi nhận về dịch hại côn trùng ảnh hưởng đến ngành trồng nấm và có nguy cơ làm tê liệt ngành nấm. Thực tế sản xuất nấm bào ngư (Pleurotus pulmonarius) ở TP.HCM và Đồng Nai cũng đang đối mặt với dịch hại do côn trùng gây ra. Côn trùng gây hại nấm trồng chưa được nghiên cứu nhiều và tài liệu ghi nhận về chúng rất ít. Chính vì vậy "Điều tra và xác định nhóm côn trùng gây hại nấm bào ngư (Pleurotus pulmonarius) trồng ở TP.HCM và Đồng Nai" sẽ là tiền đề cho các nghiên cứu tiếp theo về côn trùng gây hại nấm trồng.

\section{Vật liệu}

Côn trùng được thu thập từ các trại nấm bào ngư ở TP.HCM và Đồng Nai.

\section{Phương pháp}

\section{1. Điều tra thu thập thông tin côn trùng gây hại nấm bào ngu}

Chọn các trại trồng từ 10.000 bịch phôi trở lên, tiến hành phỏng vấn trực tiếp người trồng, điều tra các loài côn trùng gây hại nấm bào ngư, thời gian côn trùng xuất hiện nhiều, tỷ lệ thiệt hại năng suất trong khoảng thời gian côn trùng xuất hiện nhiều (Gnanerwaran \& Wijayagunasekara, 1999). Tại mỗi khu vực điều tra sẽ tiến hành điều tra 05 trại nấm. Công tác điều tra sẽ được tiến hành 2 lần/năm (01 lần mùa côn trùng xuất hiện ít, 01 lần mùa côn trùng xuất hiện nhiều).

Địa điểm điều tra: các trang trại trồng nấm bào ngư ở TP.HCM, Đồng Nai.

\subsection{Thu mẫu côn trùng gây hại nấm bào ngư tù bịch phôi, tai nấm}

Thu mẫu côn trùng tù bịch phôi:

Chọn 5 vị trí/trại nấm, mỗi vị trí lấy 5 bịch phôi, mỗi bịch phôi cân $50 \mathrm{~g}$ giá thể để đếm số lượng côn trùng và phân loại.

Thu mẫu côn trùng tì tai nấm:

Chọn 5 vị trí có tai nấm/trại dùng vợt thu mẫu côn trùng về đếm số lượng côn trùng và phân loại.

\section{Chỉ tiêu theo dõi:}

- Côn trùng thu thập được phân loại đến bộ (ngành, lớp, bộ, họ). Phân loại định danh nhóm côn trùng gây hại dựa vào các khóa phân loại định danh về hình thái trong "Borror and 
DeLong's Introduction to the Study of Insect" tác giả Triplehorn và Johnson (2005), tài liệu côn trùng hại nấm trồng (Singh \& Sharma, 2016).

- Tần suất bắt gặp của đối tượng côn trùng vào bẫy theo công thức:

$$
\operatorname{TS}(\%)=(\mathrm{ti} / \mathrm{T}) \times 100
$$

Trong đó: ti là số mẫu điều tra xuất hiện đối tượng côn trùng, $\mathrm{T}$ là tổng số mẫu điều tra

- Tỷ lệ (\%) côn trùng điều tra:

$$
\mathrm{TL}(\%)=(\mathrm{n} / \mathrm{N}) \times 100
$$

Trong đó: $\mathrm{n}$ là số côn trùng điều tra, $\mathrm{N}$ là tổng số côn trùng thu được.

\section{Kết quả}

\subsection{Kết quả điều tra thu thập thông tin côn trùng gây hại nấm bào ngu \\ * Kết quả điều tra thu thập thông tin côn trùng gây hại nấm bào ngư}

\section{Bảng 1}

\begin{tabular}{|c|c|c|c|c|c|c|c|}
\hline TT & $\begin{array}{l}\text { Họ và } \\
\text { tên }\end{array}$ & Địa chỉ & $\begin{array}{c}\text { Số bịch } \\
\text { phôi }\end{array}$ & $\begin{array}{l}\text { Mùa côn } \\
\text { trùng } \\
\text { xuất hiện } \\
\text { ít }\end{array}$ & $\begin{array}{l}\text { Mùa côn } \\
\text { trùng xuất } \\
\text { hiện nhiều }\end{array}$ & $\begin{array}{c}\text { Năng suất } \\
\text { mùa côn } \\
\text { trùng xuất } \\
\text { hiện ít } \\
\text { (bịch phôi } \\
\text { 1kg-1,2kg) }\end{array}$ & $\begin{array}{c}\text { Tỷ lệ thiệt } \\
\text { hại về năng } \\
\text { suất vào } \\
\text { mùa côn } \\
\text { trùng xuất } \\
\text { hiện nhiều }\end{array}$ \\
\hline 1 & $\begin{array}{l}\text { Nguyễn } \\
\text { Thanh } \\
\text { Hoàng }\end{array}$ & $\begin{array}{l}\text { 753, ấp Gò } \\
\text { Nô̂i, xã An } \\
\text { Nhơn Tây, } \\
\text { huyện Củ } \\
\text { Chi, } \\
\text { Tp.HCM }\end{array}$ & 10.000 & T4-T1 & T2-T3 & $\begin{array}{c}\text { 400g } \\
\text { nấm tươi }\end{array}$ & $20-30 \%$ \\
\hline 2 & $\begin{array}{l}\text { Trại } \\
\text { nấm Hải } \\
\text { Châu }\end{array}$ & $\begin{array}{l}\text { Ấp Xóm } \\
\text { Trại, xã An } \\
\text { Nhơn } \\
\text { Tây,Củ Chi }\end{array}$ & 10.000 & $\mathrm{~T} 4-\mathrm{T} 2$ & $\mathrm{~T} 2-\mathrm{T} 3$ & $\begin{array}{c}300 \mathrm{~g} \\
\text { nấm tươi }\end{array}$ & $40 \%$ \\
\hline 3 & $\begin{array}{l}\text { Trị } \\
\text { Nhóm } \\
\text { Bảy Yết }\end{array}$ & $\begin{array}{l}\text { 2/73A, ấp } \\
\text { Nhị Tân 1, } \\
\text { xã Tân Thới } \\
\text { Nhì, Hóc } \\
\text { Môn, } \\
\text { Tp.HCM }\end{array}$ & $\begin{array}{c}100.00 \\
0\end{array}$ & T5-T1 & $\mathrm{T} 2-\mathrm{T} 4$ & $\begin{array}{c}300 \mathrm{~g} \\
\text { nấm tươi }\end{array}$ & $50 \%$ \\
\hline 4 & $\begin{array}{l}\text { Trại } \\
\text { Nấm }\end{array}$ & $\begin{array}{l}\text { Tỉnh lộ 7, tổ } \\
\text { 10, âp Gót } \\
\text { Chàng, xã }\end{array}$ & $\begin{array}{c}150.00 \\
0\end{array}$ & T6-T2 & T3-T5 & $\begin{array}{c}300 \mathrm{~g} \\
\text { nấm tươi }\end{array}$ & $50 \%$ \\
\hline
\end{tabular}

Kết quả điều tra thu thập thông tin côn trùng gây hại trên nấm bào ngư tại TP.HCM 


\begin{tabular}{|c|c|c|c|c|c|c|c|}
\hline TT & $\begin{array}{l}\text { Họ và } \\
\text { tên }\end{array}$ & Địa chỉ & $\begin{array}{c}\text { Số bịch } \\
\text { phôi }\end{array}$ & $\begin{array}{l}\text { Mùa côn } \\
\text { trùng } \\
\text { xuất hiện } \\
\text { ít }\end{array}$ & $\begin{array}{l}\text { Mùa côn } \\
\text { trùng xuất } \\
\text { hiện nhiều }\end{array}$ & $\begin{array}{l}\text { Năng suất } \\
\text { mùa côn } \\
\text { trùng xuất } \\
\text { hiện ít } \\
\text { (bịch phôi } \\
\text { 1kg-1,2kg) }\end{array}$ & $\begin{array}{l}\text { Tỷ lệ thiệt } \\
\text { hại về năng } \\
\text { suất vào } \\
\text { mùa côn } \\
\text { trùng xuất } \\
\text { hiện nhiều }\end{array}$ \\
\hline & $\begin{array}{l}\text { Thanh } \\
\text { Phương }\end{array}$ & $\begin{array}{l}\text { An Nhân } \\
\text { Tây, huyện } \\
\text { Củ Chi }\end{array}$ & & & & & \\
\hline 5 & $\begin{array}{l}\text { Trung } \\
\text { tâm } \\
\text { ươm tạo } \\
\text { doanh } \\
\text { nghiệp } \\
\text { nông } \\
\text { nghiệp } \\
\text { công } \\
\text { nghệ } \\
\text { cao }\end{array}$ & $\begin{array}{l}\text { Âp 1, xã } \\
\text { Phạm Văn } \\
\text { Cội, huyện } \\
\text { Củ Chi, } \\
\text { Tp.HCM }\end{array}$ & 10.000 & T6-T2 & T3-T5 & $\begin{array}{c}300 \mathrm{~g} \\
\text { nấm tươi }\end{array}$ & $30 \%$ \\
\hline
\end{tabular}

Nguồn: Kết quả phân tích dữ liệu của nhóm nghiên cứu

Theo kết quả điều tra các trại nấm bào ngư tại TP.HCM ghi nhận mùa côn trùng gây hại nặng trên nấm bào ngư là từ tháng 02 đến tháng 05 . Thiệt hại do côn trùng gây ra làm giảm 20 $50 \%$ tổng năng suất thu hoạch. Nhóm côn trùng gây hại xuất hiện nhiều thuộc bộ hai cánh Diptera, Coleoptera. Côn trùng xuất hiện nhiều khi tai nấm hình thành hoặc một số tìm thấy trên các cây cỏ xung quanh nhà trồng nấm. Các trại nấm chưa sử dụng biện pháp hóa học trong phòng trừ dịch hại côn trùng.

\section{Bảng 2}

Kết quả điều tra thu thập thông tin côn trùng gây hại nấm bào ngư tại Đồng Nai 


\begin{tabular}{|c|c|c|c|c|c|c|c|c|}
\hline TT & $\begin{array}{c}\text { Họ và } \\
\text { tên }\end{array}$ & Địa chỉ & $\begin{array}{l}\text { Loại } \\
\text { nấm }\end{array}$ & $\begin{array}{c}\text { Số bịch } \\
\text { phồi }\end{array}$ & $\begin{array}{c}\text { Mùa côn } \\
\text { trùng } \\
\text { xuất } \\
\text { hiện ít }\end{array}$ & $\begin{array}{c}\text { Mùa côn } \\
\text { trùng } \\
\text { xuất } \\
\text { hiện } \\
\text { nhiều }\end{array}$ & $\begin{array}{c}\text { Năng } \\
\text { suất mùa } \\
\text { côn trùng } \\
\text { xuất hiện } \\
\text { ít } \\
\text { (bịch } \\
\text { phôi } \\
1,2 k g \text { ) }\end{array}$ & $\begin{array}{c}\text { Tỷ lệ thiệt } \\
\text { hại về năng } \\
\text { suất vào } \\
\text { mùa côn } \\
\text { trùng xuất } \\
\text { hiện nhiều }\end{array}$ \\
\hline 1 & $\begin{array}{l}\text { Đào } \\
\text { Xuân } \\
\text { Thủy }\end{array}$ & $\begin{array}{l}\text { Tổ 12, ấp } \\
\text { Bầu } \\
\text { Trâm, } \\
\text { Long } \\
\text { Khánh, } \\
\text { Đồng Nai }\end{array}$ & $\begin{array}{c}\text { Sản } \\
\text { xuất và } \\
\text { trồng } \\
\text { nấm } \\
\text { bào } \\
\text { ngư }\end{array}$ & 20.000 & T6-T2 & T3-T5 & $\begin{array}{l}300 \mathrm{~g} \\
\text { (tươi) }\end{array}$ & $50 \%$ \\
\hline 2 & $\begin{array}{c}\text { Phùng } \\
\text { Vănn } \\
\text { Tôn }\end{array}$ & $\begin{array}{l}\text { Tổ 16, ấp } \\
\text { Bầu trâm, } \\
\text { Long } \\
\text { Khánh, } \\
\text { Đồng Nai }\end{array}$ & $\begin{array}{l}\text { Bào } \\
\text { ngư }\end{array}$ & 10.000 & T7-T2 & T3-T6 & $\begin{array}{l}300 \mathrm{~g} \\
\text { (tươi) }\end{array}$ & $30 \%$ \\
\hline 3 & $\begin{array}{c}\text { Bùi } \\
\text { Văn } \\
\text { Lương }\end{array}$ & $\begin{array}{l}\text { Tổ 9, ấp } \\
\text { Bầu } \\
\text { Trâm, } \\
\text { Long } \\
\text { Khánh, } \\
\text { Đồng Nai }\end{array}$ & $\begin{array}{l}\text { Bào } \\
\text { ngư }\end{array}$ & 40.000 & T6-T2 & T3-T5 & $400 \mathrm{~g}$ tươi & $50-60 \%$ \\
\hline 4 & $\begin{array}{c}\text { Đỗ Văn } \\
\text { Long }\end{array}$ & $\begin{array}{l}\text { Tồ 9, ấp } \\
\text { Bầu } \\
\text { Trâm, } \\
\text { Long } \\
\text { Khánh, } \\
\text { Đồng Nai }\end{array}$ & $\begin{array}{l}\text { Bào } \\
\text { ngư }\end{array}$ & 40.000 & T6-T2 & T3-T5 & $\begin{array}{l}400 \mathrm{~g} \\
\text { (tươi) }\end{array}$ & $80-90 \%$ \\
\hline 5 & $\begin{array}{l}\text { Trại } \\
\text { nấm } \\
\text { Minh } \\
\text { Hùng }\end{array}$ & $\begin{array}{l}\text { Tổ 10, ấp } \\
\text { Bầu } \\
\text { Trâm, } \\
\text { Long } \\
\text { Khánh, } \\
\text { Đồng Nai }\end{array}$ & $\begin{array}{l}\text { Nấm } \\
\text { bào } \\
\text { ngư }\end{array}$ & $\begin{array}{c}100.00 \\
0\end{array}$ & T6-T2 & T3-T5 & $\begin{array}{l}400 \mathrm{~g} \\
\text { (tươi) }\end{array}$ & $50 \%$ \\
\hline
\end{tabular}

Nguồn: Kết quả phân tích dữ liệu của nhóm nghiên cứu

Mùa côn trùng gây hại nặng trên nấm bào ngư là từ tháng 03 đến tháng 06 . Thiệt hại do côn trùng gây ra làm giảm 30-90\% tổng năng suất thu hoạch. Nhóm côn trùng gây hại xuất hiện nhiều: bộ Diptera, bộ Coleoptera, bộ Collembola. Các nông hộ trồng nấm không chú ý nhiều về các ký chủ phụ của côn trùng gây hại. Một vài nông hộ có trại nấm trong khu vực vườn cây 
ăn trái có sự xuất hiện côn trùng thuộc bộ Diptera nhiều vào mùa trái cây chín. Các trại nấm bào chưa sử dụng biện pháp hóa học để kiểm soát côn trùng gây hại.

* Triệu chứng gây hại của côn trùng trên tai nấm và sọ̣i nấm trong bịch phôi

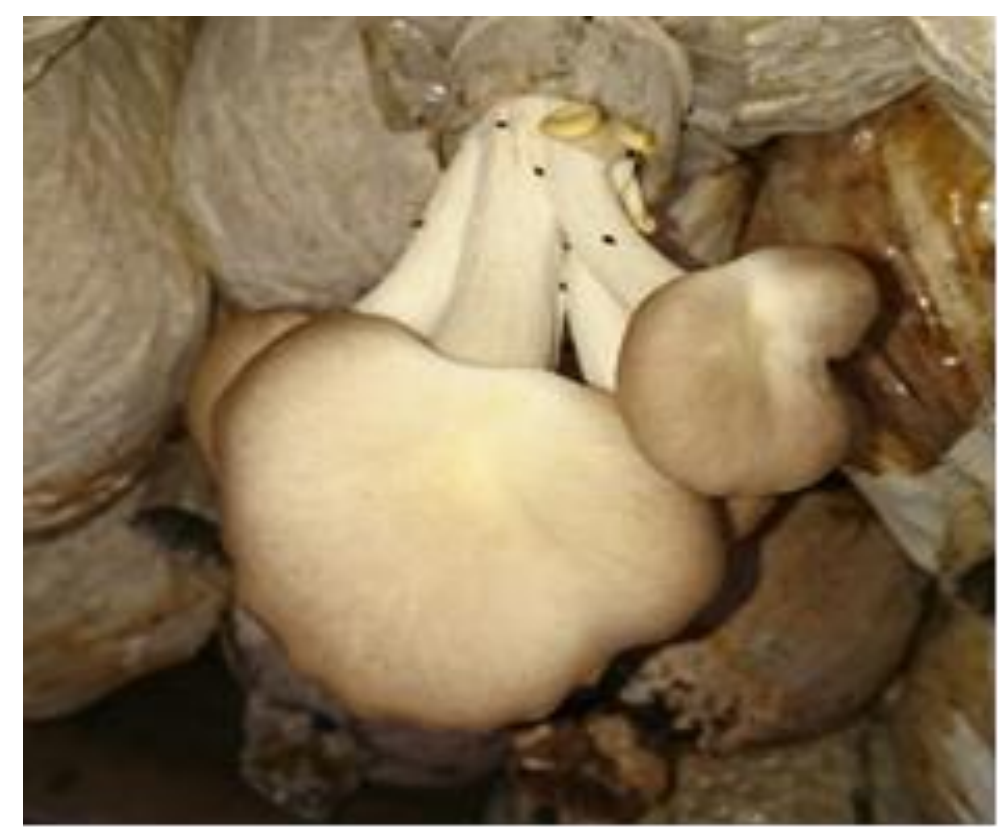

Hình 1. Triệu chứng côn trùng gây hại trên tai nấm bào ngư

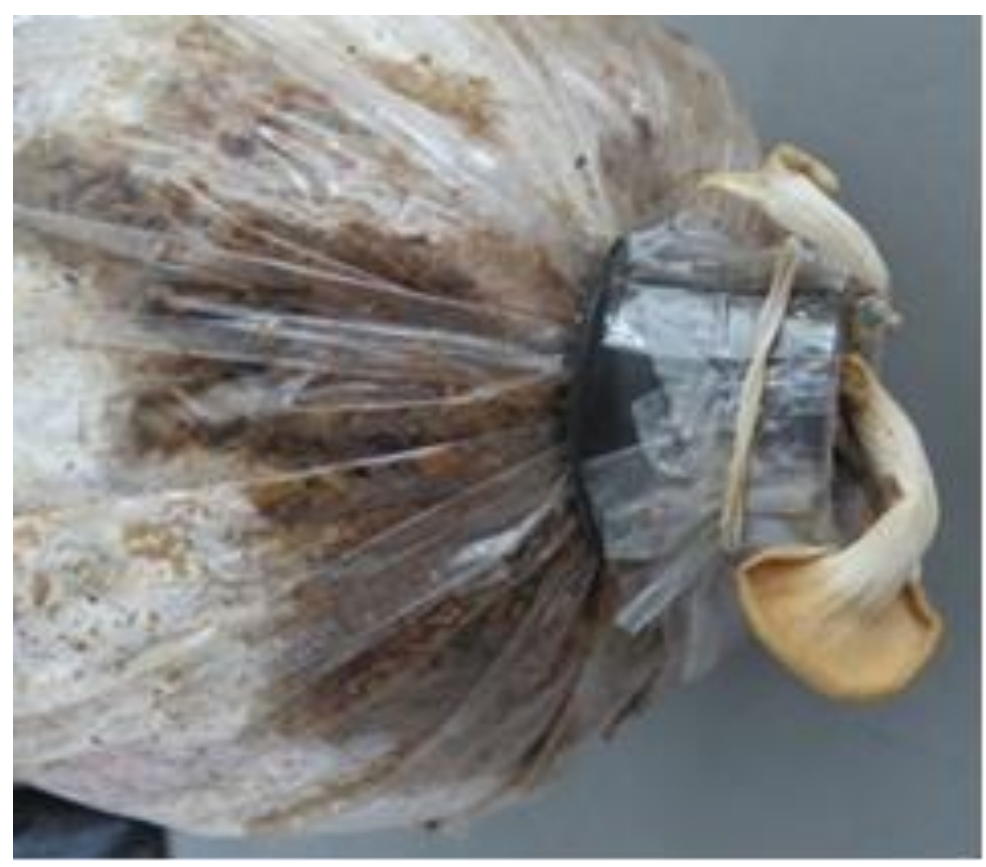

Hình 2. Triệu chứng côn trùng gây hại bịch phôi

Côn trùng gây hại nấm bào ngư thường xuất hiện mặt dưới của các tai nấm xen kẽ vào các phiếm nấm để gây hại, chúng còn tập trung nhiều ở phần chân nấm. Tai nấm bị côn trùng 
tấn công sẽ có những vết tiết dịch lỏng màu vàng và rất dễ hư hỏng nặng trong quá trình bảo quản. Các bịch phôi có sự xuất hiện côn trùng gây hại sẽ có biểu hiện tiết dịch lỏng màu vàng, theo sau đó là các loại nấm mốc (mốc xanh, mốc cam) và vi khuẩn tấn công làm hư hại hoặc thất thu cho lần thu hoạch tiếp theo.

\section{Bảng 3}

Côn trùng gây hại nấm bào ngư thu thập ở TP.HCM, Đồng Nai

\begin{tabular}{|c|c|c|c|c|}
\hline TT & Mã số & Hình ảnh & Phân loại & Vị trí gây hại \\
\hline 1 & C01 & & $\begin{array}{l}\text { Ngành Arthropoda } \\
\text { Lớp Insecta } \\
\text { Bộ Diptera } \\
\text { Họ Phoridae }\end{array}$ & Tai nấm \\
\hline 2 & $\mathrm{C} 02$ & & $\begin{array}{l}\text { Ngành Arthropoda } \\
\text { Lớp Insecta } \\
\text { Bộ Coleoptera } \\
\text { Họ Staphylinidae }\end{array}$ & Tai nấm \\
\hline 3 & $\mathrm{C} 03$ & & $\begin{array}{l}\text { Ngành Arthropoda } \\
\text { Lớp Insecta } \\
\text { Coleoptera } \\
\text { Họ Staphylinidae }\end{array}$ & Tai nấm \\
\hline 4 & C04 & & $\begin{array}{l}\text { Ngành Arthropoda } \\
\text { Lớp Insecta } \\
\text { Bộ Diptera } \\
\text { Họ Scatopsidae }\end{array}$ & Tai nấm \\
\hline 5 & C05 & & $\begin{array}{l}\text { Ngành Arthropoda } \\
\text { Lớp Insecta } \\
\text { Bộ Diptera } \\
\text { Họ Sciaridae }\end{array}$ & Tai nấm \\
\hline
\end{tabular}




\begin{tabular}{|c|c|c|c|c|}
\hline TT & Mã số & Hình ảnh & Phân loại & Vị trí gây hại \\
\hline 6 & C06 & 5 & $\begin{array}{l}\text { Ngành Arthropoda } \\
\text { Lớp Insecta } \\
\text { Bộ Collembola } \\
\text { Họ Entomobryidae }\end{array}$ & Sợi nấm \\
\hline 7 & $\mathrm{C} 07$ & $100 \mu \mathrm{m}$ & $\begin{array}{l}\text { Ngành Arthropoda } \\
\text { Lớp Insecta } \\
\text { Âu trùng bộ Diptera } \\
\text { Họ Cecidomyiidae }\end{array}$ & Sợi nấm \\
\hline 8 & $\mathrm{C} 08$ & & $\begin{array}{c}\text { Ngành Arthropoda } \\
\text { Lớp Insecta } \\
\text { Bộ Diptera } \\
\text { Họ: Phoridae }\end{array}$ & Tai nấm \\
\hline 9 & $\mathrm{C} 09$ & & $\begin{array}{l}\text { Ngành Arthropoda } \\
\text { Lớp Insecta } \\
\text { Bộ Diptera } \\
\text { Họ Cecidomyidae }\end{array}$ & Tai nấm \\
\hline
\end{tabular}

Nguồn: Kết quả phân tích dữ liệu của nhóm nghiên cứu

Côn trùng gây hại nấm bào ngư được thu thập tại các trại nấm bào ngư ở TP.HCM và Đồng Nai thuộc 3 bộ chính: Coleoptera, Diptera và Collembola. Trong các bộ côn trùng hại nấm bào ngư, bộ Diptera có thành phần đa dạng hơn 2 bộ còn lại. Đặc điểm gây hại của thành trùng thuộc bộ Coleoptera và Diptera là tai nấm, thành trùng thuộc bộ Collembola và ấu trùng thuộc bộ Diptera gây hại chủ yếu là sợi nấm trong bịch phôi.

\subsection{Kết quả thu mẫu côn trùng gây hại nấm bào ngư tù̀ bịch phôi, tai nấm}

\section{Bảng 4}

Côn trùng gây hại thu mẫu trực tiếp trên tai nấm bào ngư tại TP.HCM

\begin{tabular}{|c|c|c|c|c|}
\hline \multirow{2}{*}{ Mã số } & \multicolumn{2}{|c|}{ Mùa côn trùng xuất hiện nhiều } & \multicolumn{2}{c|}{ Mùa côn trùng xuất hiện ít } \\
\cline { 2 - 5 } & $\begin{array}{c}\text { Tần suất bắt } \\
\text { gặp }\end{array}$ & Tỷ lệ & Tần suất bắt gặp & Tỷ lệ \\
\hline C01 & $80 \%$ & $14,6 \%$ & $60 \%$ & $22,5 \%$ \\
\hline C02 & $100 \%$ & $24,9 \%$ & $40 \%$ & $9,9 \%$ \\
\hline
\end{tabular}




\begin{tabular}{|c|c|c|c|c|}
\hline \multirow{2}{*}{ Mã số } & \multicolumn{2}{|c|}{ Mùa côn trùng xuất hiện nhiều } & \multicolumn{2}{|c|}{ Mùa côn trùng xuất hiện ít } \\
\cline { 2 - 5 } & $\begin{array}{c}\text { Tần suất bắt } \\
\text { gặp }\end{array}$ & Tỷ lệ & Tần suất bắt gặp & Tỷ lệ \\
\hline C03 & $100 \%$ & $21,8 \%$ & $60 \%$ & $11,3 \%$ \\
\hline C04 & $100 \%$ & $17,9 \%$ & $100 \%$ & $30,9 \%$ \\
\hline C05 & $100 \%$ & $20,8 \%$ & $100 \%$ & $25,4 \%$ \\
\hline
\end{tabular}

Nguồn: Kết quả phân tích dữ liệu của nhóm nghiên cứu

Các đối tượng côn trùng $\mathrm{C} 01, \mathrm{C} 02, \mathrm{C} 03, \mathrm{C} 04, \mathrm{C} 05$ có tần suất bắt gặp từ $80 \%$ đến $100 \%$ ở các trại nấm điều tra vào mùa côn trùng xuất hiện nhiều. Mẫu côn trùng $\mathrm{C} 02, \mathrm{C} 03, \mathrm{C} 05$ chiếm tỷ lệ (\%) trên $20 \%$ cao hơn các mẫu còn lại. Tần suất bắt gặp và tỷ lệ $(\%)$ của các mẫu côn trùng gây hại nấm bào ngư cũng thay đổi giữa hai mùa côn trùng xuất hiện nhiều và mùa côn trùng xuất hiện ít. Vào mùa côn trùng xuất hiện ít mẫu $\mathrm{C} 01, \mathrm{C} 02, \mathrm{C} 03$ có tần xuất hiện thấp, mẫu $\mathrm{C} 04$ và $\mathrm{C} 05$ vẫn có tần xuất hiện là $100 \%$ ở các trại nấm thu mẫu. Tỷ lệ (\%) côn trùng điều tra cũng thay đổi, mẫu C01, C04, C05 có tỷ lệ (\%) trên $20 \%$.

\section{Bảng 5}

Côn trùng gây hại thu mẫu từ bịch phôi nấm bào ngư tại TP.HCM

\begin{tabular}{|c|c|c|c|c|}
\hline \multirow{2}{*}{ Mã số } & \multicolumn{2}{|c|}{ Mùa côn trùng xuất hiện nhiều } & \multicolumn{2}{c|}{ Mùa côn trùng xuất hiện ít } \\
\cline { 2 - 5 } & $\begin{array}{c}\text { Tần suất bắt } \\
\text { gặp }\end{array}$ & Tỷ lệ & $\begin{array}{c}\text { Tần suất bắt } \\
\text { gặp }\end{array}$ & Tỷ lệ \\
\hline C06 & $100 \%$ & $30,2 \%$ & $80 \%$ & $27,5 \%$ \\
\hline C07 & $100 \%$ & $45,3 \%$ & $100 \%$ & $41,3 \%$ \\
\hline
\end{tabular}

Nguồn: Kết quả phân tích dữ liệu của nhóm nghiên cứu

Vào mùa côn trùng xuất hiện nhiều, mẫu côn trùng $\mathrm{C} 06$ và $\mathrm{C} 07$ thu được từ bịch phôi có tần suất bắt gặp $100 \%$ ở các trại nấm điều tra, tỷ lệ côn trùng mẫu C07 cao hơn tỷ lệ mẫu côn trùng $\mathrm{C} 06$. Tần suất bắt gặp của các mẫu côn trùng có sự thay đổi vào mùa côn trùng xuất hiện ít, mẫu C06 có tần suất xuất hiện là $80 \%$, mẫu $\mathrm{C} 07$ vẫn có tần suất bắt gặp $100 \%$ ở các trại nấm điều tra và chiếm tỷ lệ cao hơn mẫu C06.

\section{Bảng 6}

Côn trùng gây hại thu mẫu trực tiếp trên tai nấm bào ngư tại Đồng Nai

\begin{tabular}{|c|c|c|c|c|}
\hline \multirow{2}{*}{ Mã số } & \multicolumn{2}{|c|}{ Mùa côn trùng xuất hiện nhiều } & \multicolumn{2}{c|}{ Mùa côn trùng xuất hiện ít } \\
\cline { 2 - 5 } & Tần suất bắt gặp & Tỷ lệ & Tần suất bắt gặp & Tỷ lệ \\
\hline C03 & $100 \%$ & $43,6 \%$ & $80 \%$ & $39,1 \%$ \\
\hline
\end{tabular}




\begin{tabular}{|c|c|c|c|c|}
\hline \multirow{2}{*}{ Mã số } & \multicolumn{2}{|c|}{ Mùa côn trùng xuất hiện nhiều } & \multicolumn{2}{c|}{ Mùa côn trùng xuất hiện ít } \\
\cline { 2 - 5 } & Tần suất bắt gặp & Tỷ lệ & Tần suất bắt gặp & Tỷ lệ \\
\hline C04 & $60 \%$ & $16,9 \%$ & $40 \%$ & $15,2 \%$ \\
\hline C08 & $60 \%$ & $20,9 \%$ & $20 \%$ & $13 \%$ \\
\hline C09 & $100 \%$ & $18,6 \%$ & $40 \%$ & $32.7 \%$ \\
\hline
\end{tabular}

Nguồn: Kết quả phân tích dữ liệu của nhóm nghiên cứu

Mẫu côn trùng gây hại nấm bào ngư $\mathrm{C} 03$ và $\mathrm{C} 04$ thu tại TP.HCM cũng xuất hiện tại Đồng Nai. Trong các mẫu côn trùng gây hại nấm bào ngư thu tại Đồng Nai có sự xuất hiện thêm mẫu côn trùng mới là $\mathrm{C} 08$ và $\mathrm{C} 09$. Tỷ lệ (\%) các mẫu côn trùng thay đổi theo mùa. Vào mùa côn trùng xuất hiện nhiều, mẫu C03 có tỷ lệ (\%) cao nhất $(39,1 \%)$, mẫu C04 có tỷ lệ (\%) thấp nhất $(16,9 \%)$. Vào mùa côn trùng xuất hiện ít, mẫu $\mathrm{C} 03$ vẫn có tần xuất bắt gặp cao và tỷ lệ $(\%)$ cao, mẫu $\mathrm{C} 08$ có tần suất bắt gặp và tỷ lệ (\%) thấp nhất trong số các mẫu thu được.

\section{Bảng 7}

Côn trùng gây hại thu mẫu từ bịch phôi nấm bào ngư tại Đồng Nai

\begin{tabular}{|c|c|l|c|l|}
\hline \multirow{2}{*}{ Mã số } & \multicolumn{2}{|c|}{ Mùa côn trùng xuất hiện nhiều } & \multicolumn{2}{c|}{ Mùa côn trùng xuất hiện ít } \\
\cline { 2 - 5 } & Tần suất bắt gặp & Tỷ lệ & Tần suất bắt gặp & Tỷ lệ \\
\hline C06 & $100 \%$ & $42,6 \%$ & $60 \%$ & $32,1 \%$ \\
\hline C07 & $100 \%$ & $34,4 \%$ & $100 \%$ & $41,9 \%$ \\
\hline
\end{tabular}

Nguồn: Kết quả phân tích dữ liệu của nhóm nghiên cứu

Các mẫu côn trùng thu thập được ở Bảng 7 cũng giống các mẫu côn trùng thu được từ bịch phôi tại TP.HCM. Tần suất bắt gặp của chúng là $100 \%$ vào mùa côn trùng xuất hiện nhiều. Vào mùa côn trùng xuất hiện ít, mẫu C06 có tần suất bắt gặp giảm còn $60 \%$.

\section{Thảo luận}

Đối với nấm bào ngư thì nhóm gây hại chính là nhóm ruồi thuộc bộ hai cánh (Diptera), ấu trùng ruồi (dòi) chui vào các khe của phiếm nấm, cắn phá làm hư hại nấm. Tốc độ sinh sản của chúng rất nhanh (Vo, 2016). Tác giả Trinh (2016) ghi nhận côn trùng gây hại nấm chủ yếu tập trung vào các bộ Diptera, Coleoptera và Collembola, ấu trùng xuất hiện và gây hại trong các bịch phôi, thành trùng bám vào mặt dưới tai nấm hoặc chích hút vào phiếm nấm, chúng còn là vật trung gian gây nhiễm khuẩn và nấm mốc cho bịch phôi. Trong điều tra và phân loại côn trùng gây hại nấm bào ngư ở Ấn Độ tác giả Gnanerwaran và Wijayagunasekara (1999), Singh và Sharma (2016) ghi nhận côn trùng gây hại nấm thuộc 4 bộ gồm: Diptera (3 họ: Drosophilidae, Phoridae, Sciarida), Coleoptera (3 họ: Staphylinidae, Erotylidae, Nitidulidae), Lepidoptera (họ Noctuidae) và Collembola (họ Entomobrionidae). Những đối tượng côn trùng 
thu được từ các trại nấm bào ngư tại TP.HCM và Đồng Nai được phân loại và có nhiều họ tương đồng với các nghiên cứu trên.

\section{Kết luận}

Nhóm côn trùng gây hại nấm bào ngư phổ biến thuộc bộ Coleoptera, Diptera, Collembola. Mùa côn trùng xuất hiện nhiều ở các trại trồng bào ngư tại TP.HCM bắt đầu từ tháng 02 đến tháng 05 làm giảm năng suất từ $20 \%$ đến $50 \%$. Mùa côn trùng xuất hiện nhiều ở các trại trồng bào ngư tại Đồng Nai bắt đầu từ tháng 03 đến tháng 06 làm năng suất giảm từ $30 \%$ đến $90 \%$. Thành phần côn trùng gây hại chính trên nấm bào ngư khá giống nhau giữ 2 vùng thu mẫu. Tuy nhiên về tần xuất xuất hiện của chúng khác nhau giữa các vùng. Một số đối tượng côn trùng là loài ưu thế của khu vực này nhưng tỷ lệ xuất hiện rất ít ở khu vực khác.

\section{Tài liệu tham khảo}

Gnanerwaran, R., \& Wijayagunasekara, H. N. P. (1999). Survey and indentification of insect pest of oyster mushroom (Pleurotus ostreatus). Tropical Agricultural Research and Extension, 2(1), 21-25.

Gullan, P. J., \& Cranston, P. S. (2010). The insects: An outline of entomology (4th ed.). Oxford, UK: Wiley-Blackwell.

Singh, A. U., \& Sharma, K. (2016). Pests of mushroom. Advances in Crop Science and Technology, 4, 1-6.

Trinh, X. T. (2016). Sâu bệnh chính trên nấm và biện pháp quản lý [Main pests and diseases on fungi and management measures]. Proceedings of Hội thảo trao đổi kỹ thuạt, co hộ và thách thức của ngành nấm Việt, 64-68.

Triplehorn, C. A., \& Johnson, N. F. (2005). Borror and DeLong's introduction to the study of insect (7th ed.). Boston, MA: Thompson Brooks/Cole.

Vo, A. T. (2016). Kỹ thuật trồng nấm bào ngư (Pleurotus sp.) trên mùn cưa [Technique of growing abalone mushroom (Pleurotus sp.) on sawdust]. Proceedings of Hội thảo trao đổi kỹ thuật, co hội và thách thức của ngành nấm Việt, 26-42. 